WHEN ALL ELSE FAILS 
For my daughters, Julia and Emily 


\section{WHEN ALL ELSE FAILS}

\section{Government as the Ultimate Risk Manager}

\section{David A. Moss}

HARVARD UNIVERSITY PRESS

Cambridge, Massachusetts

London, England 
Copyright $\odot 2002$ by David A. Moss

All rights reserved

Printed in the United States of America

First Harvard University Press paperback edition, 2004

Library of Congress Cataloging-in-Publication Data

Moss, David A., 1964-

When all else fails : government as the ultimate risk manager /

David A. Moss.

p. cm.

Includes bibliographical references and index.

ISBN 0-674-00757-3 (alk. paper; cloth)

ISBN 0-674-01609-2 (pbk.)

1. Risk management-United States. 2. Risk management-Government policy-United States. 3. Insurance, Government—United States.

4. Disaster relief-United States. I. Title

HD61 .M63 2002

338.5—dc21 2002017111 